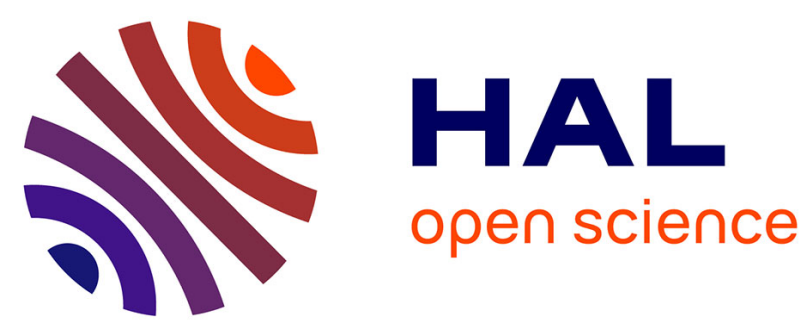

\title{
A Novel Trench-Based Triple Gate Transistor With Enhanced Driving Capability
}

R. Gay, V. Della Marca, Hassen Aziza, M. Mantelli, F. Trenteseaux, F. La Rosa, A. Regnier, S. Niel, A. Marzaki

\section{- To cite this version:}

R. Gay, V. Della Marca, Hassen Aziza, M. Mantelli, F. Trenteseaux, et al.. A Novel Trench-Based Triple Gate Transistor With Enhanced Driving Capability. IEEE Electron Device Letters, 2021, 42 (6), pp.832-834. 10.1109/LED.2021.3076609 . hal-03504285

\section{HAL Id: hal-03504285 \\ https://hal.science/hal-03504285}

Submitted on 29 Dec 2021

HAL is a multi-disciplinary open access archive for the deposit and dissemination of scientific research documents, whether they are published or not. The documents may come from teaching and research institutions in France or abroad, or from public or private research centers.
L'archive ouverte pluridisciplinaire HAL, est destinée au dépôt et à la diffusion de documents scientifiques de niveau recherche, publiés ou non, émanant des établissements d'enseignement et de recherche français ou étrangers, des laboratoires publics ou privés. 


\title{
A Novel Trench-Based Triple Gate Transistor With Enhanced Driving Capability
}

\author{
R. Gay, V. Della Marca, H. Aziza, M. Mantelli, F. Trenteseaux, F. La Rosa, A. Regnier, \\ S. Niel and A. Marzaki
}

\begin{abstract}
This paper addresses the design, implementation, and characterization of a novel highdensity Triple Gate Transistor in a $40 \mathrm{~nm}$ embedded NonVolatile Memory technology. Deep trenches are used to integrate two vertical transistors connected in parallel with the main planar transistor. Thanks to the built-in trenches, the proposed manufacturing process increases the transistor width without impacting its footprint. The voltage/current characteristics of a planar MOS structure are compared with the features of the new Triple Gate Transistor. The new architecture provides an improved driving capability, with an on-state drain current twice as high as its equivalent standard MOS, combined with a lower threshold voltage, suitable for low-voltage applications. Finally, the gate oxide and junction reliability are validated over the operating voltage range.
\end{abstract}

Index Terms-Multigate transistor, MOS devices, Trench transistor, Driving capability, Flash memory.

\section{INTRODUCTION}

$\mathrm{T}$ HE continuous development of consumer electronics underlines the high demand for low-cost and reliable microelectronic devices [1], [2]. The need for more integration has accelerated the current design trend for more scalability in almost every device parameter, such as channel length, gate dielectric thickness, supply voltage, and device leakage [3]. As most of these parameters are now reaching fundamental limits, new alternatives to the existing devices have to be identified in order to meet higher performance levels using new innovative architectures. In recent years, several devices, using multi-gate or gate-all-around transistors as an alternative to classical MOS, have emerged enabling enhancements in circuit performance [4]-[6]. Alternatively, and mostly for integrated passive devices, deep trenches are used in various ways, including as insulators, inductors, or DRAM capacitors to increase integration density [7].

The aim of this work is to build an area-efficient transistor with a high driving capability. Starting from a classical MOS transistor denoted Standard Gate Transistor (SGT), two lateral conduction channels controlled by vertical trenches enhance the

R. Gay, A. Marzaki, F. La Rosa, A. Regnier and M. Mantelli are with STMicroelectronics Rousset, 13106 Rousset, France (e-mail: romeric.gay@st.com).

S. Niel and F. Trenteseaux are with STMicroelectronics Crolles, 38926 Crolles, France.

H. Aziza and V. Della Marca are with the Institut Matériaux Microélectronique Nanosciences de Provence, UMR CNRS 7334, University of Aix-Marseille, 13451 Marseille, France.

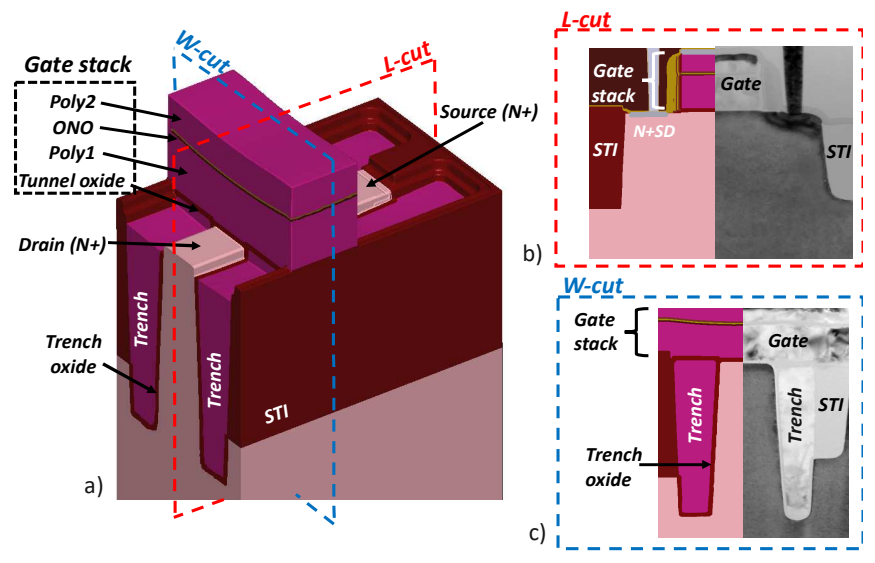

Fig. 1. (a) Triple Gate Transistor 3D view and TEM/schematic crosssections (b) in length (L) direction, (c) in width (W) direction

driving capability. This combination results in the proposed Triple Gate Transistor (TGT) [8]. Note that vertical deep trenches are currently used in embedded NOR Flash fabrication processes [9].

The next paragraph presents the TGT device. In Section III, experimental results are presented to demonstrate the functioning of the device. Finally, Section IV concludes this paper.

\section{DeVice Description ANd MANufacturing}

The TGT is integrated in a Non-Volatile Memory (NVM) environment and designed following the process flow of an embedded NOR Flash technology. No additional steps or masks are required to build the device. Fig. 1 shows (a) a 3D schematic model of the TGT and (b) (c) TEM versus schematic crossdetailed views. The TGT is created as follows: active definition and NVM implantations are first performed. Deep trenches are then etched and an oxide is grown along sidewalls of the trenches. The latter are filled with an in-situ doped polycrystalline silicon to create two vertical gates. Finally, the planar gate patterning is processed. It includes two polysilicon layers (poly1 and poly2), an oxide/nitride/oxide (ONO) interpoly dielectric and a tunnel oxide. The planar gate contact is realized on poly1 through the poly2/ONO stack while two vertical trenches contacts are shifted with respect to the gate stack and connected to trenches polycrystalline silicon. Source and drain contacts are formed with $\mathrm{n}+$ implantation. 


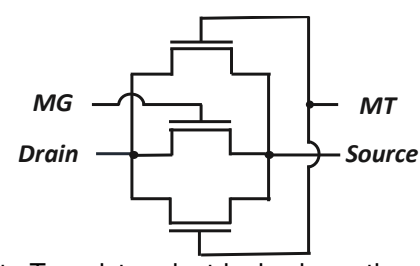

Fig. 2. Triple Gate Transistor electrical schematic

Fig. 2 maps the electrical schematic model of the TGT. The TGT is modeled by three MOS transistors connected in parallel, and therefore has three conduction channels. The first channel, which is located between the Drain and the Source, is controlled by the stacked gate (Poly1+tunnel oxide) and belongs to the device denoted by MOS Gate (MG) transistor. The second and third channels, which are also located between the Drain and the Source, are controlled by the trenches (shorted) and belong to the devices denoted by MOS Trenches (MT) transistors.

\section{EXPERIMENTAL RESULTS}

Fig. 3 shows I-V characteristics in linear mode with drain voltage $\mathrm{V}_{\mathrm{D}}=0.1 \mathrm{~V}$ and in saturated mode with $\mathrm{V}_{\mathrm{D}}=2 \mathrm{~V}$ for: (a) MG and SGT, (b) MT and (c) TGT. The TGT characteristics include the contribution of three transistors: the MG and two trench transistors. A summary of the most relevant parameters in saturated mode is shown in Table I of Fig. 3 (d). The driving current parameter $\left(\mathrm{I}_{\mathrm{on}}\right)$ is extracted for gate voltage $\mathrm{V}_{\mathrm{G}}=4 \mathrm{~V}$ and the threshold voltage $\left(\mathrm{V}_{\mathrm{t}}\right)$ is extracted for the drain current $\mathrm{I}_{\mathrm{D}}=0.1 \mu \mathrm{A}$. Moreover, we highlight the $\mathrm{I}_{\mathrm{on}} / \mathrm{V}_{\mathrm{t}}$ ratio that can be used as a design parameter figure of merit. In Fig. 3 (a) the standard SGT MOS is compared with the MG transistor of the triple-gate device. The conduction currents are equivalent, while the MG threshold voltage slightly decreases due to the presence of vertical transistors. The latter impact the oxide thickness at the edges of the active substrate. Based on Fig. 3 (a)-(c), we observe that the TGT provides an $\mathrm{I}_{\text {on }}$ driving current $\left(463 \mu \mathrm{A}\right.$ for $\left.\mathrm{V}_{\mathrm{D}}=2 \mathrm{~V}\right)$ three times higher than the SGT $(143 \mu \mathrm{A}$ for $V_{D}=2 \mathrm{~V}$ ), because the TGT benefits from a triple conduction (i.e., trenches conduction in addition to the classical MOS channel conduction). Regarding the leakage current ( $\left.\mathrm{I}_{\mathrm{off}}\right)$ extracted at $\mathrm{V}_{\mathrm{G}}=0 \mathrm{~V}$, the TGT and $\mathrm{SGT}$ values are comparable
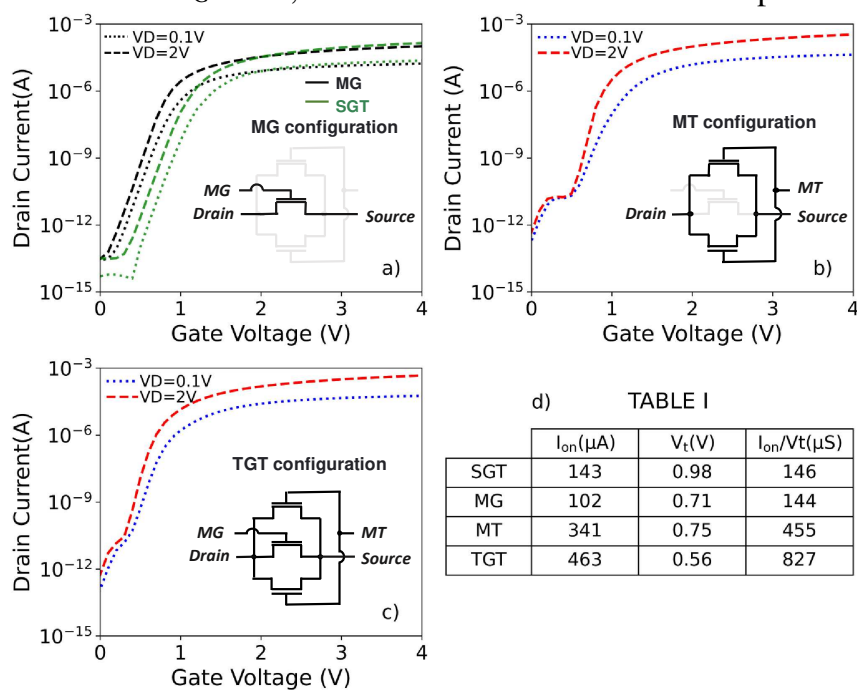

Fig 3. I-V characteristics in linear and saturated conduction modes for: (a) MOS Gate and SGT, (b) MOS Trenches and (c) Triple Gate Transistor. (d) Comparison metrics in saturated mode. (less than $1 \mathrm{pA}$ ). Quantitative results are provided in Fig. 3 (d) MOS Gate $I_{\text {on }}(102 \mu \mathrm{A})$ represents around $25 \%$ of the TGT $I_{\text {on }}$ current and MOS Trenches $\mathrm{I}_{\text {on }}(341 \mu \mathrm{A})$ represents $75 \%$ of the TGT $\mathrm{I}_{\mathrm{on}}$ current. Moreover, we can see a higher threshold voltage for the SGT $\left(\mathrm{V}_{\mathrm{t}}=0.98 \mathrm{~V}\right)$ compared to the TGT $\left(\mathrm{V}_{\mathrm{t}}=\right.$ $0.56 \mathrm{~V})$. This difference is explained by a thinner trench oxide thickness and by the MT geometry. In Fig. 3 (b) we can note at the beginning of $\mathrm{I}-\mathrm{V}$ characteristics (around $\mathrm{I}_{\mathrm{D}}=10 \mathrm{E}^{-11} \mathrm{~A}$ and $\mathrm{V}_{\mathrm{G}}=0.2 \mathrm{~V}$ ) a hump effect due to the parasitic transistors formed by the active rounding [10], [11]. This effect is reflected in the TGT characteristics (Fig. 3 (b)) even though its impact is negligeable.

In Fig. 4 (a), the test results of gate voltage stress are provided for the TGT and the SGT. We note that the tunnel-oxide breakdown is reached at $15 \mathrm{~V}$ for both devices. However, the MG gate current start increasing before the gate current of the SGT does. This early leakage current is caused by an oxide weakness at trench-gate corners induced by the manufacturing process (as already mentioned before during $\mathrm{V}_{\mathrm{t}}$ extraction). Regarding the MT transistor, it starts to leak at $3 \mathrm{~V}$ with a breakdown voltage of $10 \mathrm{~V}$. This lower value is explained by the irregular thickness of the trench oxide caused by a nonuniform oxide growth along sidewalls. In Fig. 4 (b) are featured the test results of Drain/Bulk junction voltage stress for the TGT and the SGT in off-state $\left(\mathrm{V}_{\mathrm{G}}=0 \mathrm{~V}\right)$. Comparable Drain/Bulk junction breakdown characteristics are reported for TGT and SGT. These last stress tests demonstrate the robustness of the TGT: indeed, the maximum gate and drain voltages reported for the addressed technology are respectively $\mathrm{V}_{\mathrm{G}}=4 \mathrm{~V}$ and $\mathrm{V}_{\mathrm{D}}=3 \mathrm{~V}$, far from the breakdown threshold (around 7.7 V).

Fig. 5 reports the evolution of the driving current $\left(\mathrm{I}_{\mathrm{on}}\right)$ versus different device footprints with constant L. The blue linear curve which is related to the SGT is compared with the characteristics of the proposed TGT. For equivalent $\mathrm{I}_{\mathrm{on}}$ current, the trench transistors integration allows to divide the device
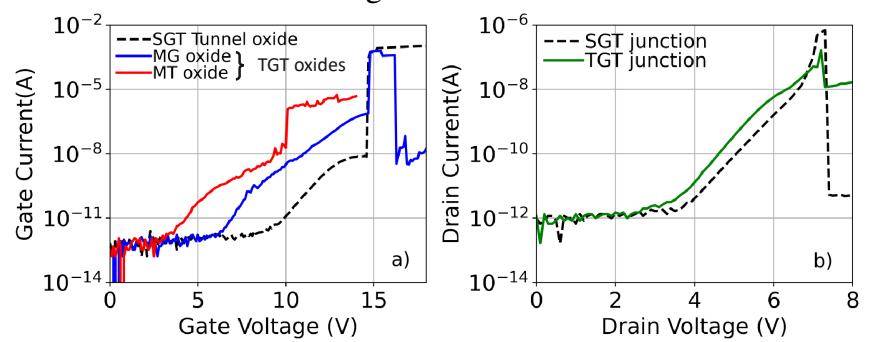

Fig. 4. (a) Gate voltage stress I-V characteristics. (b) Drain/Bulk junction voltage stress I-V characteristics (average over three measurements).

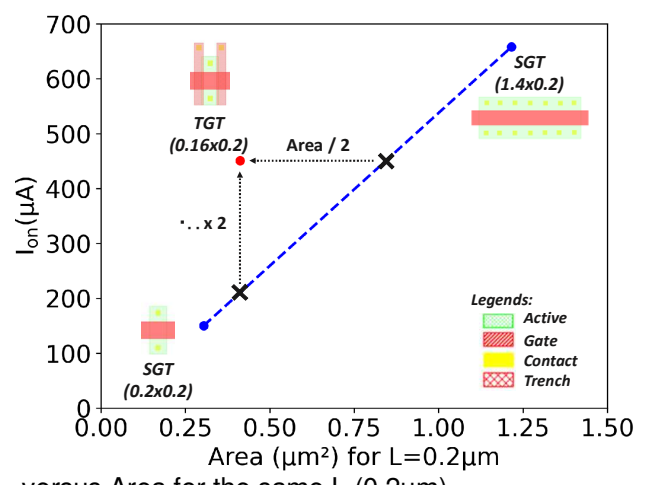

Fig. 5. I $\mathrm{I}_{\mathrm{n}}$ versus Area for the same $\mathrm{L}(0.2 \mu \mathrm{m})$ 
area by a factor two. Therefore, for an equivalent area, $\mathrm{I}_{\mathrm{on}}$ current is doubled if the TGT architecture is considered.

\section{CONCLUSION}

In this paper we propose a new transistor architecture denoted by Triple Gate Transistor that uses deep polysilicon trenches to build side transistor. The TGT manufacturing process and its different conduction modes are first introduced. The experimental results demonstrate the functionality and reliability of the TGT based on I-V characteristics and stress tests results. The driving capability of the TGT device is two times higher than its equivalent standard MOS counterpart. The $\mathrm{I}_{\text {off }}$ current is maintained constant and a $\mathrm{V}_{\mathrm{t}}$ decrease is reported. The new proposed architecture can provide significant chiplevel area savings as only half the silicon area is needed to reach an equivalent driving capability. For future work, we plan to use the TGT device with decorrelated gates (i.e., two different control signals for the trench transistors) to explore new opportunities for low-voltage and analog applications. 


\section{REFERENCES}

[1] J. Lin and K. Huang, "A High-Performance Polysilicon Thin-Film Transistor Built on a Trenched Body," in IEEE Transactions on Electron Devices, vol. 55, no. 9, pp. 2417-2422, Sept. 2008, doi: 10.1109/TED.2008.927667.

[2] D. Xue, F. Song, J. Wang and X. Li, "Single-Side Fabricated p+Si/Al Thermopile-Based Gas Flow Sensor for IC-Foundry-Compatible, HighYield, and Low-Cost Volume Manufacturing," in IEEE Transactions on Electron Devices, vol. 66, no. 1, pp. 821-824, Jan. 2019, DOI: 10.1109/TED.2018.2878469.

[3] M. T. Bohr and I. A. Young, "CMOS Scaling Trends and Beyond," in IEEE Micro, vol. 37, no. 6, pp. 20-29, November/December 2017, doi: 10.1109/MM.2017.4241347.

[4] Ferain I, Colinge CA, Colinge JP. "Multigate transistors as the future of classical metal-oxide-semiconductor field-effect transistors." Nature. 2011 Nov;479(7373):310-316, doi: 10.1038/nature10676

[5] C. Erine, J. Ma, G. Santoruvo and E. Matioli, "Multi-Channel AlGaN/GaN In-Plane-Gate Field-Effect Transistors," in IEEE Electron Device Letters, vol. 41, no. 3, pp. 321-324, March 2020, doi: 10.1109/LED.2020.2967458
[6] J. P. Colinge, "Multiple-gate SOI MOSFETs.", Solid State Electron, 48, 897-905 (2004), doi: 10.1016/j.sse.2003.12.020

[7] H. Sunami. "Development of three-dimensional MOS structures from trench-capacitor DRAM cell to pillar-type transistor", International Conference on Solid-State and Integrated Circuits Technology Proceedings, ICSICT, pp. 853-856, $2008 . \quad$ doi: 10.1109/ICSICT.2008.4734677.

[8] Patent: "Transistor MOS à triple grille et procédé de fabrication d'un tel transistor", by A. Marzaki and R. Gay, INPI number: FR 2009976

[9] F. L. Rosa, S. Niel, A. Regnier, F. Maugain, M. Mantelli and A. Conte, "40nm embedded Select in Trench Memory (eSTM ${ }^{\mathrm{TM}}$ ) Technology Overview," 2019 IEEE 11th International Memory Workshop (IMW), Monterey, CA, USA, 2019, pp. 1-4, doi: 10.1109/IMW.2019.8739731.

[10] S. Schwantes, J. Fuerthaler, T. Stephan, M. Graf, V. Dudek, T. Barry, G. Miller, and J. Shen, "Characterization of a new hump-free device structure for smart power and embedded memory technologies", Microelectronic Engineering, vol. 81, pp. 132-139, 2005, doi: 10.1016/j.mee.2005.04.007

[11] J. Locati, V. Della Marca, C. Rivero, P. Fornara, A. Regnier, S. Niel, K. Coulié "AC stress reliability study on a novel vertical MOS transistor for non-volatile memory technology," Microelectronics Reliability, pp. 7 , 2020. doi: 10.1016/j.microrel.2020.113810 